This item was submitted to Loughborough's Research Repository by the author.

Items in Figshare are protected by copyright, with all rights reserved, unless otherwise indicated.

\title{
Interacting with adaptive architecture
}

PLEASE CITE THE PUBLISHED VERSION

https://doi.org/10.1145/3137113

PUBLISHER

ACM $\odot$ The Author

VERSION

AM (Accepted Manuscript)

PUBLISHER STATEMENT

This work is made available according to the conditions of the Creative Commons Attribution-NonCommercialNoDerivatives 4.0 International (CC BY-NC-ND 4.0) licence. Full details of this licence are available at: https://creativecommons.org/licenses/by-nc-nd/4.0/

\section{LICENCE}

CC BY-NC-ND 4.0

\section{REPOSITORY RECORD}

Jaeger, Nils. 2019. "Interacting with Adaptive Architecture". figshare. https://hdl.handle.net/2134/27653. 


\section{Interacting with Adaptive Architecture}

Nils Jäger, University of Nottingham/Loughborough University

The design and fabrication of adaptive architecture are often driven by technological possibilities, such as employing the latest construction materials and processes, the newest sensors, better actuators, or novel data-processing capabilities. Less frequently, specific interactions between inhabitant and architecture are the driving force behind the design of adaptive architecture. However, it is as vital to advance our understanding of these interactions as it is to explore the new technologies enabling them.

Interactions between humans and buildings will become increasingly important to consider in the design of future architecture. More and more home-automation devices and platforms developed as part of the Internet of Things (IOT) are rapidly becoming capable of communicating with activity and biomedical sensors that track our behavior in real time. Indeed, our mobile phones already manage both: IoT data and devices as well as activity and medical data from sensors we wear. It is a small step to imagine that our personal behavioural and physiological data, such as our current heart rate, might drive actuations in our home, such as ventilation and lighting systems.

There are several reasons why interactions between inhabitants and architecture feature less prominently in architectural and $\mathrm{HCl}$ research than explorations of novel technologies do. One reason is that interaction design does not include enough architectural thinking, as Mikael Wiberg has argued in this forum [1]. On the other hand, the discipline of architecture lacks in interaction-based thinking.

In fact, when architects talk about the inhabitants of architecture, they speak about the experience of-not so much the interaction with-traditional static architecture. Often using a phenomenological approach, architects describe and explain how we perceive architecture with our bodies. This might be the sensing of the shape, proportion, and sequence of space(s), as well as the texture, color, and structural features of materials, including the use of light and shadow. Much of this caters to the visual sense. And although a growing number of architectural theorists, such as Juhanni Pallasmaa, are arguing for the importance of taking more than the visual sense into account when designing architecture, these discussions still mainly concern static architectural spaces and structures as opposed to responsive interactive environments.

\section{Embodiment-A Brief Excursion}

Recently, a new approach has emerged that complements the phenomenological account of the experience of architecture [2]: the enactive approach to cognition. This approach is particularly well suited to adaptive architecture, as we will see later. The enactive approach 
to cognition is a relatively new addition to the larger realm of embodied cognition, which explains that the brain not only creates abstract concepts of the world but also makes use of the entire body to extract information from and make sense of the world.

Within embodied cognition, the enactive approach is part of the so-called 4Es: embodied, extended, embedded, and enacted. In short, embodied refers to cognition being driven by the constitution of our physical bodies, such as having two eyes for stereoscopic vision, allowing us to see in three dimensions. We also extend our body into the world through our haptic [3], gustatory, olfactory, visual, and audial senses to extract information. All this always occurs in a specific context in which we are embedded. This context affects our action potential or affordances, and it allows us to make use of resources around us to "offload" cognitive processes into the environment. Think of a Post-it on your screen to remind you to get milk on the way home. Embodied, extended, and embedded all contribute to the enacted part of the 4Es, which refers to the body actively engaging with the world around it. We actively seek information about our environments, be they physical or social. For example, we walk around a building to experience all its sides, getting to know the different qualities of light, different smells, different sounds, and so on. As we walk, we might also stick out our hand and touch the building's facade to feel the texture of materials. 


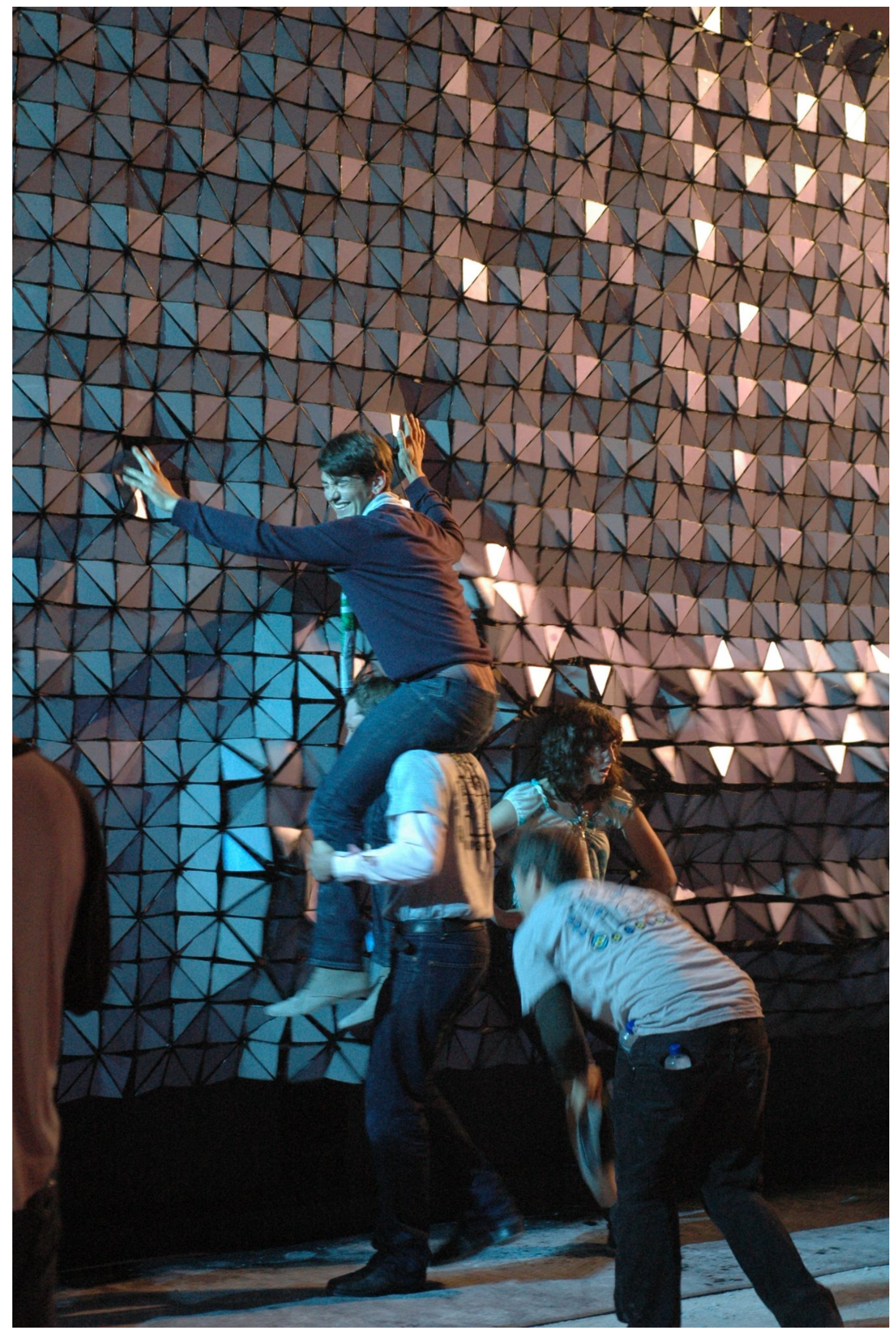

Figure 1. HypoSurface, an interactive architectural element. 
Proponents of the enactive approach argue that because of this activity in exploring and making sense of our surroundings, there is an obvious close relationship between us and the world around us. Hanne De Jaegher and Ezequiel Di Paolo [4] explain that enacted cognition crucially consists of multi-sensory explorations of the world, while emphasizing the coupling between agents and the environment and their continuous embodied interaction.

Moreover, these continuous interactions with other agents (mostly humans) and objects (including architecture) help us to understand the world and ourselves in it. Especially when we engage in interactions with other active agents, we engage in a process of "participatory sense-making": The actions and reactions of all agents contribute to our emerging knowledge and experiences about the world.

\section{Enaction and Adaptive Architecture}

According to the enactive approach, we interact with the world in a reciprocal manner: We interact with and shape our environments, and our environments shape our interactions. In some sense, these interactions are very much like the feedback loop explained by Holger Schnädelbach in this forum [5]. In the following, we will see how this feedback loop can develop its own dynamic, which we as designers can then use to create interesting, meaningful-even beneficial-interactions with adaptive architecture.

Enactive embodiment: A mechanism. Thomas Fuchs explains how we enact our embodied connection with another person through small bodily expressions and impressions [6]. He uses the following example: Person A is angry. This is manifested in typical facial and gestural expressions. Person A internally perceives their own anger as tension in the muscles, higher body temperature, increased heartbeat-a general arousal. However, these elements also express the angry state to others, making it perceptible. Person B notices these expressions and reacts with their own body to the anger of $A$. For example, B might suddenly tighten their muscles and jump in surprise at person A's raised/sharper voice. Person B's reaction is an expression of their emotional state, which person A perceives as an impression. Person A then reacts to this expression, and so forth. This process can become autonomous and continue without either agent actively trying to influence it. Thus, a continuous interaction cycle emerges that Fuchs calls inter-bodily resonance. 


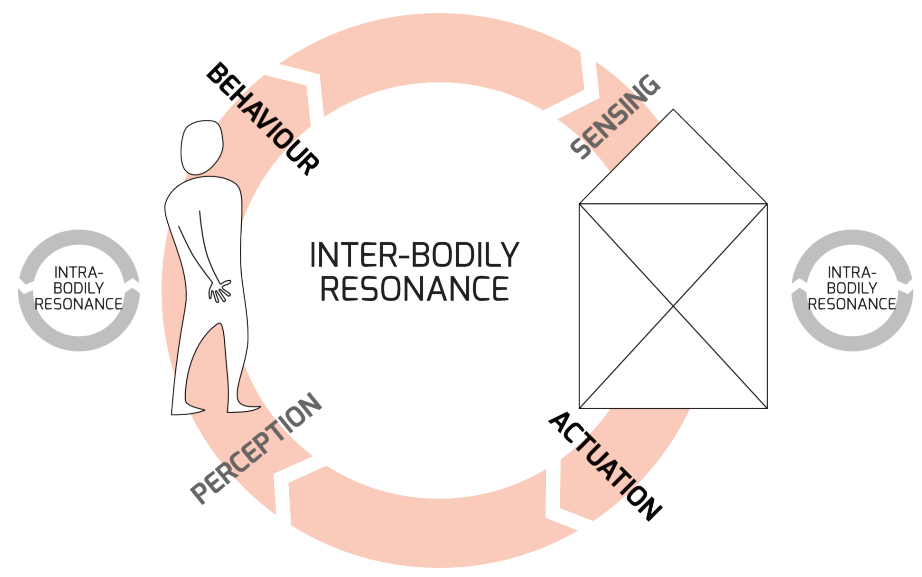

Figure 2. Interbodily resonance between inhabitant and adaptive architecture

This mechanism of potentially autonomous micro-adjustments between interaction partners can be transferred to and used for our interactions with adaptive architecture. Arguably, adaptive architecture has both perceptive and expressive abilities through its use of sensors and actuators, which are coordinated by software-in sum, a sensorimotor system. The inhabitant expresses a behavior, which the space senses. The sensory data is then processed and sent to actuators to express environmental behavior, which the inhabitant perceives. This illustrates the biofeedback loop as described by Schnädelbach. However, what Fuchs describes operates in both directions: Each partner participates equally in the interaction. So, what happens if the environment not only reflects the behavior of its inhabitant but also becomes proactive?

Reciprocal control. In one of our studies, we investigated the reciprocity of interactions between inhabitant and adaptive space by trying to have the environment lead inhabitants to different behaviors [7]. We used an adaptive structure called ExoBuilding, which moves up and down in response to a person's breathing, thereby establishing a biofeedback loop. To reverse this feedback loop, we took control away from participants after some time and without their knowing. We first adaptively blended inhabitant behavior and automated environmental behavior, and then progressively faded out inhabitant input until only automated environmental behavior remained. Following this transition of control, the environment slowed down its movement pattern. Most participants followed this change and adjusted their breathing (one group knowingly, another unknowingly) to the slowing movement of the adaptive environment. In other words, they synchronized their behavior with the environment. Architectural spaces that can predictably lead inhabitants to specific behaviors might, for example, be used in therapy, rehabilitation, or for relaxation purposes.

Synchrony. We have seen how the enactive approach applies to the interaction between an adaptive environment and one inhabitant. Now let's look at how an adaptive space can affect the interaction between two inhabitants. Indeed, the enactive approach already provides for such a scenario [4]: A general example used to illustrate this relation is the 
situation of two people walking toward each other in a narrow corridor. At some point, they must take action to avoid walking into each other. Often, they both move toward the same wall of the corridor. Then, realizing that this would again cause a collision, they both move to the other side, mirroring each other's movements. This dance continues until one of them breaks the interactional coupling. In this example, the narrowness of the corridor shaped the interaction between the two people. Now imagine that the environment actively participates in such a coordination of its inhabitants' behaviors.

There are numerous situations - other than in narrow corridors - in which we already coordinate our own behavior with that of others. For example, we engage in dancing, playing sports, or making music. If we perceive this coordination to be successful, we might feel a stronger sense of cohesion with our partner(s). And interpersonal synchrony has further benefits, which others have extensively researched. Among them are: the establishment of rapport, positive effects on social perception, improvement of memory, increased self-awareness and other-awareness, increased social-emotional development, improved self-regulation in children, and improvements in work performance while reducing anxiety. Thus, if adaptive environments facilitated synchrony between inhabitants, we might experience positive effects on the life we spend inside adaptive buildings.

First indications are that such coordination between people might be possible to achieve with adaptive architecture. For example, we conducted a study with yoga practitioners in an adaptive architecture prototype [8]. The breathing of two practitioners was measured and their synchronicity expressed through a projected graphic. This graphic faded in and out based on how synchronized the two were: High synchrony meant a sharp image; low synchrony meant a blurry image. Seeing a visualization of their synchrony motivated practitioners to stay synchronized or try to regain synchrony, making the yoga experience more relational and group focused. Practitioners perceived this emerging quality of the session as very positive.

To explore synchrony further, we built another prototype of adaptive architecture called $W A B I$. It kinetically responds to how its two inhabitants breathe and can do this for each inhabitant independently. WABI can process data from both inhabitants to create different interaction modes and data mappings:

- Inhabitants can be surrounded by their own data-a one-to-one mapping of their data to their immediate surroundings.

- Their data can be aggregated-WABI's response to the average of inhabitant data is equal for both inhabitants.

- The data can be crisscrossed-inhabitant $A$ is surrounded by the data/behavior of inhabitant $B$ and vice versa. 
An initial exploratory study of WABI (currently in preparation for publication) indicates that crisscrossing data seems to facilitate synchrony between inhabitants more than other interaction modes.

\section{An (En)Action Plan}

The increasing evidence of the effects of adaptive environments on their inhabitants alongside developments of technology and how we gather and share data about us now suggest that $\mathrm{HCl}$ thinking is becoming useful to and perhaps even necessary for architectural thinking. Thus, architects need to begin considering the intended interactions between inhabitants and digitally augmented architectural space. They will need to ask: What meaning can inhabitants gain from interacting with adaptive architecture? What benefits can such interactions have for them? What contexts and what spaces would benefit from interactive architectural elements? Who should be leading such human-building interactions (see our work on reciprocal control)? When do these interactions occur on an individual or group level? And how do they scale to multi-inhabitant scenarios? These are only a few questions that point toward an exciting future of our interactions with adaptive architecture.

\section{Endnotes}

1. Wiberg, M. Interaction design meets architectural thinking. interactions 22, 2 (2015), 60-63; http://doi.org/10.1145/2732936

2. Jelić, A., Tieri, G., De Matteis, F., Babiloni, F., and Vecchiato, G. The enactive approach to architectural experience: A Neurophysiological perspective on embodiment, motivation, and affordances. Frontiers in Psychology 7, 608 (2016), 658-20; http://doi.org/10.3389/fpsyg.2016.00481

3. I mean haptic here in the sense of actively exploring an object (or environment) by moving one's body. Or, as Gibson (1966) put it, haptic perception is "the sensibility of the individual to the world adjacent to his body by use of his body." Hence, this includes proprioception/kinaesthesia, the sense of our own body in relation to its environment.

4. De Jaegher, H. and Di Paolo, E. Participatory sense-making. Phenomenology and the Cognitive Sciences 6, 4 (2007), 485-507; http://doi.org/10.1007/s11097-007-9076-9

5. Schnadelbach, H. Adaptive architecture. Interactions 23, 2 (2016), 62-65; http://doi.org/10.1145/2875452.

6. Fuchs, T. The Phenomenology of Affectivity. OUP Oxford, 2013. 
7. Jäger, N., Schnädelbach, H., Hale, J., Kirk, D., and Glover, K. Reciprocal control in adaptive environments. Interacting with Computers 29, 4 (Jul. 2017), 512-529; http://doi.org/10.1093/iwc/iww037

8. Moran, S., Jäger, N., Schnädelbach, H., and Glover, K. ExoPranayama: A biofeedbackdriven actuated environment for supporting yoga breathing practices. Personal and Ubiquitous Computing 20, 2 (Apr. 2016), 261-275; http://doi.org/10.1007/s00779-0160910-3

At the time of writing, Nils Jäger was a Research Fellow in the Mixed Reality Laboratory, University of Nottingham, UK. He is now a lecturer in Digital Architecture at the School of Architecture, Building and Civil Engineering, Loughborough University, UK. A trained architect, he investigates the bodily relationship between inhabitants and (adaptive) architecture. This work often crosses the disciplines of architecture, $\mathrm{HCl}$, and psychology/philosophy.n.jaeger@lboro.ac.uk

\section{Insights}

- As buildings become increasingly interactive, the effects of such interactions on inhabitants need to be understood.

- The enactive approach to cognition can help us to design more meaningful interactions with adaptive architecture. 